\title{
The prevalence of iron deficiency and anemia and their impact on survival in patients at a cardio-oncology clinic
}

\author{
E. Čiburienè ${ }^{1 *}$, J. Čelutkienè ${ }^{1}$, S. Aidietiené ${ }^{1}$, G. Ščerbickaité ${ }^{1}$ and A. R. Lyon 2,3
}

\begin{abstract}
Background: Iron deficiency (ID) and anemia are common in both heart failure (HF) and cancer patients and are associated with poor quality of life and survival. The aims of this study were (1) to evaluate the prevalence, types, and confounding factors of ID and anemia in patients referred to cardio-oncology clinic, and (2) identify the association between iron metabolism parameters and survival of cardio-oncology patients.
\end{abstract}

Methods: We assessed iron, ferritin, hemoglobin concentrations, transferrin saturation (TSAT), cancer type, brain natriuretic peptide (BNP), left ventricular ejection fraction (LVEF), kidney function, cardiovascular risk factors and survival in 599 patients who were referred to cardio-oncology clinic from 2011 to 2017.

ID was defined by a TSAT < 20\%, absolute iron deficiency (AID) with a serum ferritin level $<100 \mu \mathrm{g} / \mathrm{L}$ while serum ferritin level of $\geq 100 \mu \mathrm{g} / \mathrm{L}$ was considered as functional iron deficiency (FID) and TSAT $\geq 20 \%$ was considered as no ID.

Results: The prevalence of ID, AID, and FID was 46, 31, and 15\% of study patients, respectively. Anemia was present in approximately half (54\%) of the patients with any ID.

Multivariate Cox analyses showed that male gender (HR 1.704 [1.207-2.404] $p=0.002)$; previous cancer history (HR 1.879 [1.079-3.272] $p=0.026)$; elevated BNP (HR 2.126 [1.258-3.590] $p=0.005)$; TSAT< $20 \%$ (HR 1.721 [1.214-2.439] $p=0.002)$; ferritin $\geq 100 \mu \mathrm{g} / \mathrm{L}$ (HR 2.008 [1.088-3.706] $p=0.026)$; serum iron concentration $<12 \mu \mathrm{mol} / \mathrm{L}$ (HR 2.292 [1.614-3.255] $p<0.001)$; FID (HR 2.538 [1.1618-3.981] $p<0.001)$ and anemia (HR 2.462 [1.734-3.495] $p<0.001)$ were significantly associated with increased risk of all-cause death.

Conclusions: About half of cardio-oncology patients had anemia and iron deficiency, with the absolute type being twice as prevalent as the functional one. Patients with breast, gastrointestinal, and genitourinary cancer were affected more often. Both anemia and iron deficiency independently predicted all-cause mortality. Future studies are required to confirm ID as a risk factor and evaluate the clinical benefits of iron replacement therapy.

Keywords: Cardio-oncology, Cancer, Iron deficiency, Anemia, Survival

\footnotetext{
* Correspondence: egle.ciburiene@gmail.com

${ }^{1}$ Clinic of Cardiac and Vascular Diseases, Institute of Clinical Medicine, Faculty of Medicine, Vilnius University, M.K.Čiurlionis str. 21, 03101 Vilnius, Lithuania Full list of author information is available at the end of the article
}

(c) The Author(s). 2020 Open Access This article is licensed under a Creative Commons Attribution 4.0 International License, which permits use, sharing, adaptation, distribution and reproduction in any medium or format, as long as you give appropriate credit to the original author(s) and the source, provide a link to the Creative Commons licence, and indicate if changes were made. The images or other third party material in this article are included in the article's Creative Commons licence, unless indicated otherwise in a credit line to the material. If material is not included in the article's Creative Commons licence and your intended use is not permitted by statutory regulation or exceeds the permitted use, you will need to obtain permission directly from the copyright holder. To view a copy of this licence, visit http://creativecommons.org/licenses/by/4.0/. The Creative Commons Public Domain Dedication waiver (http://creativecommons.org/publicdomain/zero/1.0/) applies to the data made available in this article, unless otherwise stated in a credit line to the data. 


\section{Introduction}

\section{Iron homeostasis}

Iron is a fundamental element of the human body that is responsible for energy metabolism, oxygen transport and exchange, electron transfer, DNA synthesis and repair, cell growth, and proliferation [1].

Iron circulates in plasma bound to the glycoprotein transferrin, which sustains iron in a soluble form, shielding iron from developing of toxic radicals and via transferrin receptors delivers it into cells [2].

Under normal conditions, serum ferritin reflects the iron stores' status, which correlates with the iron amount in liver biopsy samples. However, ferritin is an acute-phase protein, and infections, cancer, and liver disorders can increase serum ferritin levels, which do not correlate with real iron storage and this complicates the ID's diagnosis [3].

\section{Iron deficiency in patients with cancer}

Iron metabolism and regulation of homeostasis are often altered in patients with cancer. It is associated with the status of chronic disease, chronic blood loss, and nutritional deficiencies [4]. Furthermore, dividing cancer cells consume a large amount of iron for their DNA replication, growth, and metastatic process $[5,6]$. The bone marrow infiltration by tumor cells or metastases and myelosuppressive chemotherapy effects are also significant for iron homeostasis [7].

Recent evidence revealed that ferritin might stimulate tumor angiogenesis, enhance tumor proliferation, and suppress the host's immune system [8]. Elevated ferritin in cancer cells is associated with cancer progression, resistance to therapies, and worse prognosis [9]. Moreover, some cancer cells can produce ferritin, making them partly independent of external iron supply or plunder iron from surrounding cells and tissues and store it as ferritin to maintain their rapid proliferation [10].

Therefore, transferrin saturation is a more reliable marker of bioavailable iron in cancer patients [11]. ID in cancer patients is defined as TSAT $<20 \%$ with further classification of AID and FID by ferritin values: AID with exhausted iron storage (ferritin concentration $<100 \mu \mathrm{g} /$ L) and FID with regular iron resources but restricted its availability and transport [5, 7, 12-14].

Timely diagnosis and appropriate treatment of ID are vital in cancer patients because complications are the onset or worsening of pre-existing anemia, with such symptoms as impaired exercise capacity and fatigue, deteriorated quality of life, which affects adherence to chemotherapy and may negatively influence therapeutic results $[12,15]$.

Iron deficiency in patients with chronic heart failure (HF) In recent years there has been growing interest in ID of HF patients as it may affect almost half of them, causing adverse clinical consequences. ID could be explained by the inflammatory process commonly observed in chronic $\mathrm{HF}$, which creates a reduction in iron absorption and blockage in the reticuloendothelial system (RES), leading to FID. The gradual depletion of iron stores also may be caused by low iron intake, malabsorption, or blood loss, evoking AID.

It was noticed that compromised iron transport, consistent with FID, is associated with worse clinical status and increased risk of mortality in patients with chronic HF compared with patients who have decreased iron storage (AID) [16].

\section{Background}

Advances in cancer research, diagnostics and treatment improve survival rates for many cancers. However, it varies among cancer types, stage, patients' age and comorbidities. All influencing factors must be evaluated to increase survivability. ID and anemia are common in cancer patients and has a negative impact on the quality and expectancy of life. This study's aims were (1) to evaluate the prevalence, types, and confounding factors of ID and anemia in patients referred to cardio-oncology clinic, and (2) identify the association between iron metabolism parameters and survival of cardio-oncology patients.

\section{Methods}

Data were collected retrospectively in consulting referrals to the cardio-oncology clinic at Royal Brompton Hospital between 1st February 2011 and 31st May 2017 (599 patients). A median follow-up was 23.8 months.

Patients were referred from oncologists, surgeons, other cardiologists, and primary care. Common reasons for referrals to cardio-oncology clinic were (1) high baseline cardiovascular risk before an operation or cancer therapy; (2) treatment for asymptomatic or symptomatic left ventricular systolic dysfunction; (3) chemotherapyinduced vasospasm; (4) QTc prolongation and hypertension induced by vascular endothelial growth factor (VEGF) inhibitors therapy; (5) evaluation of cardiac tumors; (6) direct cardiac complications of cancer (carcinoid valvular heart disease, cardiac amyloidosis, pericardial effusion, direct invasion).

Patients with 31 types of cancer were consulted. We grouped rare cancer types into "others" (gastrointestinal stromal (GIST), mesotheliomas, neuroendocrine and nasooropharyngeal tumors).

Iron, TSAT, ferritin, hemoglobin concentrations, and red blood cell indices (mean corpuscular volume (MCV) and mean corpuscular hemoglobin $(\mathrm{MCH})$ ) were analyzed in all patients at admission to cardio-oncology clinic.

Reduced transferrin saturation was defined as $<20 \%$, low iron concentration - less than $12 \mu \mathrm{mol} / \mathrm{L}$. 
ID was defined as TSAT $<20 \%$, AID - TSAT $<20 \%$ and serum ferritin of $<100 \mu \mathrm{g} / \mathrm{L}$, FID $-\mathrm{TSAT}<20 \%$ and serum ferritin $\geq 100 \mu \mathrm{g} / \mathrm{L}$. TSAT $\geq 20 \%$ was considered as no ID (Non-ID).

Anemia was diagnosed for a hemoglobin (Hgb) concentration $<13.0 \mathrm{~g} / \mathrm{L}$ in men and $<12.0 \mathrm{~g} / \mathrm{L}$ in women. Microcytic anemia was defined as mean corpuscular volume $(\mathrm{MCV})<84 \mathrm{fl}$ and mean corpuscular hemoglobin $(\mathrm{MCH})$ $<28 \mathrm{pg}$; macrocytic $-\mathrm{MCV}>98 \mathrm{fl}$ and $\mathrm{MCH}>34 \mathrm{pg}$.

A reduced LVEF was defined as $<50 \%$, elevated BNP was accepted as $>20 \mathrm{ng} / \mathrm{L}$.

\section{Statistical analysis}

We used descriptive statistics to describe distributions or variables. Continuous variables are presented as minimal (min), median or mean, maximal values (max), and standard deviation (SD). For categorical variables, frequencies and proportions (percentages) of each category or combination of categories are presented. An independent sample t-test was used to compare the values of means between two groups. To identify the significant differences between more than two groups, one-way ANOVA was performed. The independence of two categorical variables was tested using the Chi-square test. Logistic regression was used for multivariate analyses based on models, including the factors with a $p$-value $\leq 0.10$ in univariate analyses. Odds ratios with $95 \%$ confidence intervals (CI) were reported. Risk factors for overall survival were assessed by univariate Cox regression analysis. Overall survival was defined as the time from the patient's first visit to the cardio-oncology clinic to death from any cause. A two-tailed $p$-value of less than 0.05 considered being significant. Statistical analysis was performed using Statistical Analysis System (SAS) package version 9.2.

\section{Results}

Data were available from 599 consecutive patients and their baseline characteristics are summarized in Table 1.

Ferritin variations among study patients showed in Fig. 1.

\section{Confounding factors of ID}

In univariate analyses gender, cancer location, elevated BNP value, DM, kidney dysfunction, and anemia were associated with an ID. In multivariate analysis taking into account all these parameters except elevated BNP and other cancer locations than breast (they appeared not statistically significant factors and were excluded from the final model), AID was independently associated with female gender (OR 2.4 [1.47; 3.84], $p<0.01$ ), anemia (OR 1.9 [1.33; 2.91], $p<0.01$ ), DM (OR 2.3 [1.26; 4.14], $p<0.01$ ), whereas FID - with breast cancer (OR $0.4[0.19 ; 0.84], p<0.05)$ and anemia (OR 5.0 [2.98; $8.45], p<0.01)$.

\section{ID subgroups analysis}

Differences between iron deficiency subgroups are shown in Table 2.

AID was most often observed in patients with breast $(40.9 \%)$, gastrointestinal $(36.5 \%)$, and thyroid cancer $(35.8 \%)$, whereas FID - in patients with lung cancer (41.7\%), sarcoma (23.9\%) and gynecological cancer (20\%). AID and FID distribution among cancer types are presented in Fig. 2.

\section{Anemia in cancer patients}

Almost half of all study patients had anemia. Anemia was diagnosed significantly more often in men (108 [45.8\%]) than in women $(136[37.5 \%])(p=0.032)$, and men in the anemia group were older than women: 65.17 vs. 58.86 years, respectively $(p=0.003)$.

Normocytic normochromic anemia was the most frequent type in 164 (67.2\%) anemic patients when microcytic hypochromic anemia was diagnosed in only 56 (22.9\%).

Anemia was diagnosed in $70.4 \%$ of patients in FID group and $45.8 \%$ in AID group.

Patients with anemia more frequently had impaired kidney function $(26.6 \%$ vs $15.3 \%, p<0.001)$ and diabetes (53\% vs $39.8 \%, p=0.054$ ).

Low serum iron concentration was determined in $91.6 \%$ of anemic patients ( $59 \%$ females), while TSAT < $20 \%$ and ferritin $<100 \mu \mathrm{g} / \mathrm{L}$ was found in 59 and $42.2 \%$ of anemic patients, respectively. The incidence of anemia in AID, FID, and non-ID patients with different cancer locations showed in Fig. 3. Iron status among patients without anemia is presented in Fig. 4.

\section{Prognostic impact of ID in cancer patients}

During the study period, 159 patients died, more men than women (35.6\% vs. $20.7 \%)$.

Deceased patients were older and almost $90 \%$ of them had elevated BNP; their ferritin levels were higher, but they had lower mean serum iron concentration.

Patients in the ID group died more frequently than in the non-ID ( $p=0.003$, see Table 1$)$; the risk of death in patients with FID was almost four times higher than in patients with AID (OR 3.797 [2.319; 6.249], $p<0.01$ ).

Deceased patient characteristics are presented in Table 3.

The relation between iron status and survival showed in Fig. 5.

The prognostic impact of different factors is presented in Table 4. Using univariate Cox regression model we found that male gender, cancer location except hematologic and other type of cancer (gastrointestinal HR 2.991 [1.570-5.699] $p<0.001$; genitourinary HR $2.530[1.359-4.709] \quad p=0.003 ;$ gynecological 4.426 [2.300-8.517] $p<0.001$; hematological 1.640 [0.689- 
Table 1 Baseline characteristics of patients

\begin{tabular}{|c|c|c|c|c|}
\hline Baseline Characteristics & $\begin{array}{l}\text { All } \\
n=599^{1}(\%)\end{array}$ & $\begin{array}{l}\text { ID } \\
n=275(45.9 \%)\end{array}$ & $\begin{array}{l}\text { Non-ID } \\
n=324(54.1 \%)\end{array}$ & $P$-value \\
\hline Age (mean $\pm S D$, range) & $60.4 \pm 15.3(16-93)$ & $61.5 \pm 15.2(16-88)$ & $59.4 \pm 15.4(18-93)$ & $p=0.089$ \\
\hline Sex & & & & $p=0.038$ \\
\hline Female & $363(60.6 \%)$ & $179(65.1 \%)$ & $184(56.8 \%)$ & \\
\hline Type of visit & & & & $p=0.085$ \\
\hline Pre-surgery/pre-chemotherapy & 239 (39.9\%) & $122(44.4 \%)$ & 117 (36.1\%) & \\
\hline Current cancer treatment & $243(40.6 \%)$ & 107 (38.9\%) & $136(42.0 \%)$ & \\
\hline Post-treatment & $117(19.5 \%)$ & $46(16.7 \%)$ & $71(21.9 \%)$ & \\
\hline Cancer location & & & & $p=0.101$ \\
\hline Breast & $181(30.2 \%)$ & $86(31.3 \%)$ & $95(29.3 \%)$ & \\
\hline Genitourinary & $80(13.4 \%)$ & $32(11.6 \%)$ & $48(14.8 \%)$ & \\
\hline Sarcoma & $67(11.2 \%)$ & $29(10.5 \%)$ & $38(11.7 \%)$ & \\
\hline Gastrointestinal & $63(10.5 \%)$ & $33(12.0 \%)$ & $30(9.3 \%)$ & \\
\hline Thyroid & $53(8.8 \%)$ & $25(9.1 \%)$ & $28(8.6 \%)$ & \\
\hline Gynecologic & $50(8.3 \%)$ & $26(9.5 \%)$ & $24(7.4 \%)$ & \\
\hline Hematologic & $41(6.8 \%)$ & $12(4.4 \%)$ & $29(9.0 \%)$ & \\
\hline Others & $34(5.7 \%)$ & $12(4.4 \%)$ & $22(6.8 \%)$ & \\
\hline Melanoma & $18(3.0 \%)$ & $12(4.4 \%)$ & $6(1.9 \%)$ & \\
\hline Lung & $12(2.0 \%)$ & $8(2.9 \%)$ & $4(1.2 \%)$ & \\
\hline Previous cancer history & $39(6.5 \%)$ & $19(6.9 \%)$ & $20(6.2 \%)$ & $p=0.716$ \\
\hline \multicolumn{5}{|l|}{ Cardiovascular risk factors } \\
\hline Hypertension & $224(37.5 \%)$ & $110(40 \%)$ & $114(35.2 \%)$ & $p=0.225$ \\
\hline Diabetes & $67(11.2 \%)$ & $42(15.3 \%)$ & $25(7.7 \%)$ & $p=0.003$ \\
\hline Dyslipidaemia & $79(13.2 \%)$ & $31(11.3 \%)$ & $48(14.8 \%)$ & $p=0.202$ \\
\hline Previous HF & $20(3.3 \%)$ & $11(4.0 \%)$ & $9(2.8 \%)$ & \\
\hline Prior CAD & $55(9.1 \%)$ & $28(10.2 \%)$ & $27(8.3 \%)$ & \\
\hline Valvular Heart Disease & $17(2.8 \%)$ & $9(3.3 \%)$ & $8(2.5 \%)$ & \\
\hline Smoking & $47(7.8 \%)$ & $21(7.6 \%)$ & $26(8 \%)$ & $p=0.966$ \\
\hline Elevated BNP & $463(77.3 \%)$ & $218(79.3 \%)$ & $245(75.6 \%)$ & $p=0.523$ \\
\hline LVEF (mean \pm SD, range, \%) & $57.5 \pm 11.0(20-85)$ & $57.7 \pm 10.6(21-80)$ & $57.4 \pm 11.3(20-85)$ & $p=0.750$ \\
\hline LVEF $<50 \%$ & $107(17.9 \%)^{2}$ & $46(16.7 \%)$ & $61(18.8 \%)$ & $p=0.504$ \\
\hline Kidney dysfunction & & & & $p=0.006$ \\
\hline $\mathrm{GFR}<60 \mathrm{ml} / \mathrm{min} / 1.73 \mathrm{~m}^{2}$ & $119(19.9 \%)$ & $68(24.7 \%)$ & $51(15.7 \%)$ & \\
\hline TSAT (mean \pm SD, range, $\%)$ & $23 \pm 14.1(3.0-99.0)$ & $13.6 \pm 14.1(3.0-19.0)$ & $30.9 \pm 14.7(20.0-99.0)$ & $p<0.001$ \\
\hline Median & 20 & 14 & 26 & \\
\hline Ferritin $(\mu \mathrm{g} / \mathrm{L}$, mean $\pm S D$, range) & $188.0 \pm 297.9(6.0-1500.0)$ & $125.7 \pm 201.9(6.0-1500.0)$ & $241.2 \pm 351.8(11.0-1500.0)$ & $p<0.001$ \\
\hline Ferritin $<100 \mu \mathrm{g} / \mathrm{L}$ & $343(57.3 \%)$ & $186(67.6 \%)$ & $157(48.4 \%)$ & \\
\hline Ferritin $\geq 100 \mu \mathrm{g} / \mathrm{L}$ & $252(42.1 \%)$ & $88(32.0 \%)$ & $164(50.6 \%)$ & \\
\hline Serum iron (umol/L, mean $\pm S D$, range) & $14.3 \pm 7.9(1.6-76)$ & $9.2 \pm 5.1(1.6-76)$ & $18.6 \pm 7.2(8.6-61.0)$ & $p<0.001$ \\
\hline Iron $<12 \mathrm{umol} / \mathrm{L}$ & $253(42.2 \%)^{3}$ & $229(83.3 \%)$ & $24(7.4 \%)$ & \\
\hline Anemia & $244(40.7 \%)$ & $144(52.4 \%)$ & $100(30.9 \%)$ & $p<0.001$ \\
\hline Normocytic & $164(27.4 \%)$ & $93(33.8 \%)$ & $71(21.9 \%)$ & \\
\hline Microcytic & $56(9.4 \%)$ & $47(17.1 \%)$ & $9(2.8 \%)$ & \\
\hline Macrocytic & $24(4 \%)$ & $4(1.4 \%)$ & $20(6.2 \%)$ & \\
\hline
\end{tabular}


Table 1 Baseline characteristics of patients (Continued)

\begin{tabular}{|c|c|c|c|c|}
\hline Baseline Characteristics & $\begin{array}{l}\text { All } \\
n=599^{1}(\%)\end{array}$ & $\begin{array}{l}\text { ID } \\
n=275(45.9 \%)\end{array}$ & $\begin{array}{l}\text { Non-ID } \\
n=324(54.1 \%)\end{array}$ & $P$-value \\
\hline Deceased during study period & $159(26.5 \%)$ & $89(32.4 \%)$ & $70(21.6 \%)$ & $p=0.003$ \\
\hline
\end{tabular}

Some data was missing: ferritin concentration in 4 patients, hemoglobin concentration in 8 patients, LVEF in 5 patients, and iron concentration in 1 patient. $B N P$ Brain natriuretic peptide, CAD Coronary artery disease, GFR Glomerular filtration rate, HF Heart failure, ID Iron deficiency, LVEF Left ventricular ejection fraction, Non-ID No iron deficiency, SD Standard deviation, TSAT Transferrin saturation.

3.903] $p=0.263$; lung HR 8.354 [3.116-22.397] $p<$ 0.001 ; melanoma HR $3.176 \quad[1.080-9.341] \quad p=0.036$; other HR $2.112[0.888-5.024] p=0.091$; sarcoma HR 3.760 [2.021-6.997] $p<0.001$; thyroid HR 2.152 [1.0234.526] $p=0.043)$, previous cancer history, elevated BNP ( $>20 \mathrm{ng} / \mathrm{L}$ ), $\mathrm{TSAT}<20 \%$, ferritin $\geq 100 \mu \mathrm{g} / \mathrm{L}$, serum iron concentration $<12 \mathrm{umol} / \mathrm{L}$ and anemia were significantly associated with increased risk of all-cause death.

\section{Discussion}

These are the first data on prevalence and patterns of iron metabolism disorders in cardio-oncology patients, showing an independent association of ID and all-cause mortality. The present study's critical findings are that ID is ubiquitous in cardio-oncology patients, AID is more prevalent than FID, and the iron deficit is a significant factor associated with prognosis and clinical outcomes in this population. However, ID often remains undiagnosed and untreated properly in cancer patients because the assessment of iron status under inflammatory conditions is complicated and demands more attention to iron homeostatic mechanisms when intravenous iron administration alone or in combination with erythropoiesis-stimulating agents is safe and more effective than oral iron forms and also decreases the requirement for transfusion $[17,18]$.

Our results revealed a high prevalence of ID (46\%) in cardio-oncology patients. ID is always caused by a disbalance between iron availability and requirement. This balance is strictly regulated but could be disturbed in cancer patients by a combination of a chronic inflammatory process, alimentary deficiencies, blood loss, increased iron consumption by cancer cells, bone marrow infiltration, and chemotherapy-caused myelosuppression [4-7]. The high prevalence of ID in such cancer types as gastrointestinal, genitourinary, gynecological, lung may be explained by the increased risk of bleeding. Although, some cancer cells can increase the intracellular iron stores for their proliferative and metastatic purposes, thus reducing iron store levels. Moreover, ID is associated with a more advanced cancer stage and a more malignant phenotype $[5,19]$.

FID is reported as the dominant iron deficiency mechanism in oncology patients triggered by the inflammatory process associated with cancer or its treatment [4, 16]. The elevated ferritin values are associated with acute infection, kidney dysfunction, liver disorders, and more aggressive disease [3]. Although FID is associated with worse clinical status and increased risk of mortality in these patients, we found that in cardio-oncology patients' population AID proportions were twice as high as FID, similar to patients with chronic HF but without cancer $[16,20]$. However, ID, FID, and anemia were more reliable predictors of mortality than elevated BNP in our study. Surprisingly, cardiovascular risk factors $(\mathrm{AH}$, diabetes, dyslipidemia, smoking, and previous cardiac disease) showed no statistically significant effect on mortality among our patients.

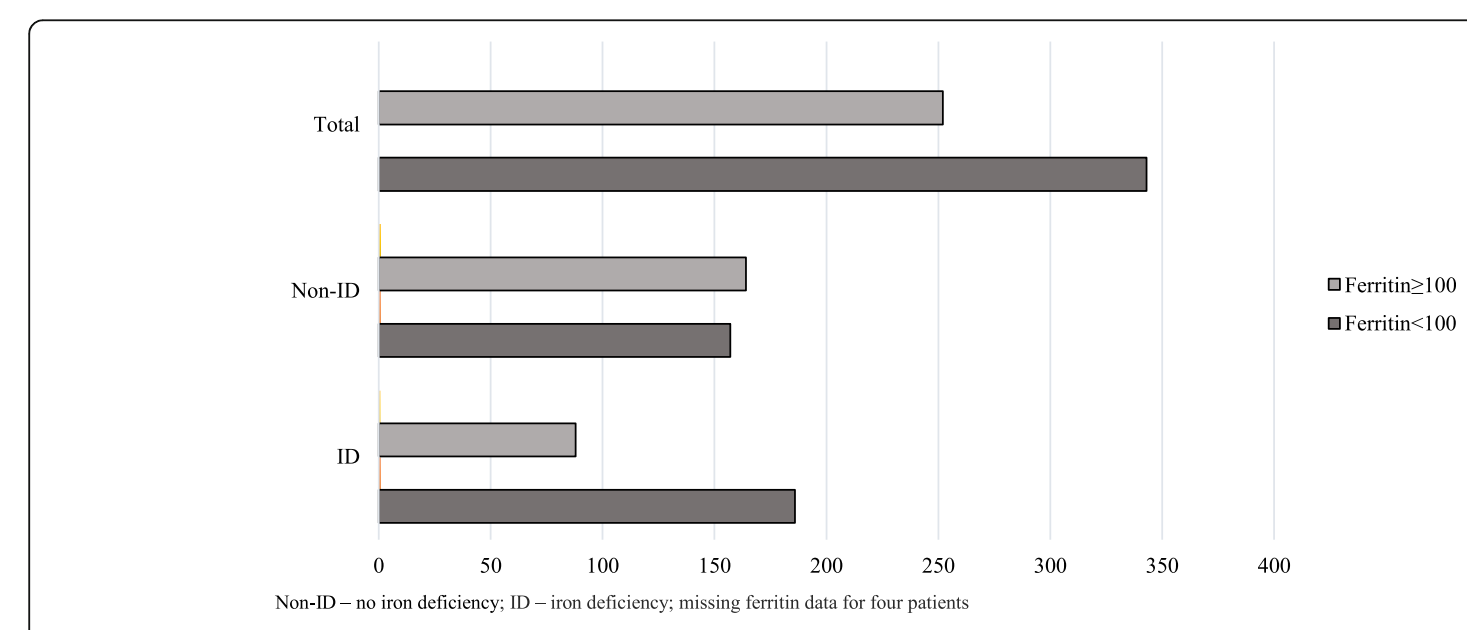

Fig. 1 Ferritin values in patients with different iron status. Non-ID - no iron deficiency; ID - iron deficiency; missing ferritin data for four patients 
Table 2 Differences between patients with FID and AID

\begin{tabular}{|c|c|c|c|}
\hline Baseline Characteristics & $\begin{array}{l}\text { FID } \\
n=88 / 599(14.7 \%)\end{array}$ & $\begin{array}{l}\text { AID } \\
n=186 / 599(31.1 \%)\end{array}$ & $P$-value \\
\hline Age (mean $\pm S D$, range) & $62.9 \pm 13.9(18-87)$ & $60.9 \pm 15.8(16-86)$ & $p=0.310$ \\
\hline \multicolumn{4}{|l|}{ Sex } \\
\hline Female & $42(47.7 \%)$ & $137(73.3 \%)$ & $p<0.001$ \\
\hline Cancer location & & & $p<0.000$ \\
\hline Breast & $12(13.6 \%)$ & $74(39.6 \%)$ & 1 \\
\hline Genitourinary & $14(15.9 \%)$ & $18(9.6 \%)$ & \\
\hline Sarcoma & $16(18.2 \%)$ & $13(7 \%)$ & \\
\hline Gastrointestinal & $10(11.4 \%)$ & $23(12.3 \%)$ & \\
\hline Thyroid & $6(6.8 \%)$ & $19(10.2 \%)$ & \\
\hline Gynaecologic & $10(11.4 \%)$ & $16(8.6 \%)$ & \\
\hline Hematologic & $6(6.8 \%)$ & $6(3.2 \%)$ & \\
\hline Others & $3(3.4 \%)$ & $9(4.8 \%)$ & \\
\hline Melanoma & $6(6.8 \%)$ & $6(3.2 \%)$ & \\
\hline Lung & $5(5.7 \%)$ & $3(1.6 \%)$ & \\
\hline \multicolumn{4}{|l|}{ Cardiovascular risk factors } \\
\hline Hypertension & $29(32.9 \%)$ & $81(43.5 \%)$ & $p=0.11$ \\
\hline Diabetes & $12(13.6 \%)$ & $29(15.6 \%)$ & $p=0.02$ \\
\hline Dyslipidaemia & $6(6.8 \%)$ & $24(12.9 \%)$ & $p=0.142$ \\
\hline Smoking & $21(23.9 \%)$ & $31(16.7 \%)$ & $p=0.6$ \\
\hline Elevated BNP & $76(89.4 \%)$ & $142(75.9 \%)$ & $p=0.01$ \\
\hline LVEF (mean $\pm S D$, range, \%) & $56.5 \pm 11.3(22-85)$ & $58.2 \pm 10.4(21-80)$ & $p=0.226$ \\
\hline LVEF $<50 \%$ & $19(22.1 \%)$ & $24(13 \%)$ & $p=0.03$ \\
\hline \multicolumn{4}{|l|}{ Kidney dysfunction } \\
\hline $\mathrm{GFR}<60 \mathrm{ml} / \mathrm{min} / 1.73 \mathrm{~m}^{2}$ & $68(77.3 \%)$ & $139(74.3 \%)$ & $p=0.598$ \\
\hline TSAT (mean \pm SD, range, \%) & $13.7 \pm 3.8(4.0-19.0)$ & $13.5 \pm 4.2(3.0-19.0)$ & $p=0.707$ \\
\hline Median & 14 & 14 & \\
\hline Ferritin $(\mu \mathrm{g} / \mathrm{L})($ mean $\pm \mathrm{SD}$, range $)$ & $311.5 \pm 274.5(100.0-1468.0)$ & $37.8 \pm 23.7(6.0-99.0)$ & $p<0.001$ \\
\hline Median & 220.5 & 31.5 & \\
\hline \multicolumn{4}{|l|}{ Serum iron } \\
\hline (umol/L)(mean $\pm S D$, range) & $8.6 \pm 7.8(1.6-76)$ & $9.55 \pm 3.1(1.6-17)$ & $p=0.264$ \\
\hline Anemia & $62(70.4 \%)$ & $82(45.8 \%)$ & $p=0.03$ \\
\hline Deceased during the study period & $45(51.1 \%)$ & 44 (23.5\%) & $p<0.001$ \\
\hline
\end{tabular}

FID Functional iron deficiency, AID Absolute iron deficiency, SD Standard deviation, HF Heart failure, CAD Coronary artery disease, BNP Brain natriuretic peptide, LVEF Left ventricular ejection fraction, GFR Glomerular filtration rate, TSAT Transferrin saturation

It is well known that anemia is widespread (28-45\%) and strongly associated with higher mortality in cancer patients [21, 22]. We determined that almost half of our patients with ID (41\%) had anemia, and more than half (59\%) died during the study period. The prevalence of anemia and mortality was higher among FID.

We found out that diabetes and kidney dysfunction was significantly associated with ID. In case of diabetes, it could be explained by chronic inflammation and kidney dysfunction as a complication. On the other hand, reduced iron stores are associated with increased hemoglobin A1C concentration, leading to a falsepositive diabetes diagnosis [23]. In chronic kidney disease ID is often caused by reduced hepcidin excretion by the kidneys, increased blood loss, and treatment with erythropoietin-stimulating agents [3].

In summary, iron status should be assessed in all cancer and HF patients not only for the reason to prevent or correct anemia and improve patient's symptoms but to potentially reduce mortality and 


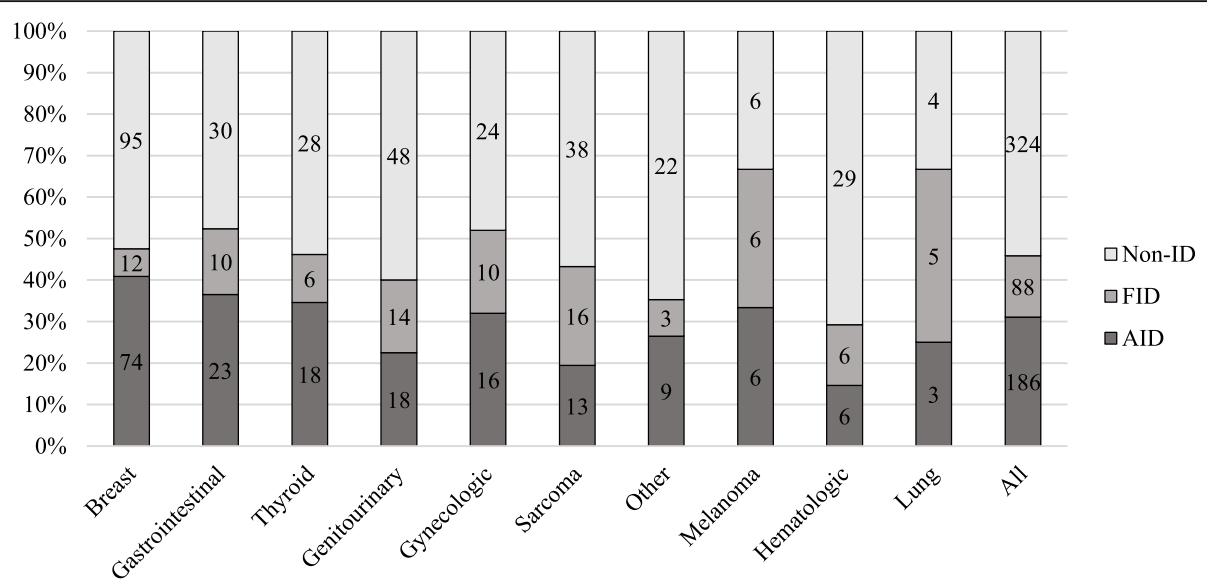

AID - absolute iron deficiency; FID - functional iron deficiency; Non-ID - no iron deficiency.

Fig. 2 Cancer location in different iron status groups of patients. AID - absolute iron deficiency; FID - functional iron deficiency; Non-ID - no iron deficiency

contribute to improving survival rates in this complex group of patients.

Our results differ from other ID research data in cancer patients because patients referred to cardio-oncology clinic were older, had concomitant cardiovascular disease or its risk factors, and other severe comorbidities.

\section{Study limitations}

Presented data were obtained retrospectively from only one blood sample at the admittance to the cardiooncology clinic, and there was impossible to take into account random fluctuations of iron parameters. Some data was missing. A wide variety of different types of cancer were included in this study, but some cancer types were rare for statistically significant results. In multivariate analysis, such cancer types as lung, melanoma, thyroid, and hematologic were grouped with "Others" due to small groups' size.

Measurements of TSAT have some limitations. In inflammatory diseases, the expression of transferrin receptors is reduced, resulting in a falsely high transferrin concentration, which decreases the TSAT even when the circulating iron level is stable [13]. However, malnutrition and chronic disease may diminish the synthesis of transferrin, which would raise TSAT. There are also significant (17-70\%) diurnal fluctuations in TSAT concentration that may challenge interpreting this value [11].

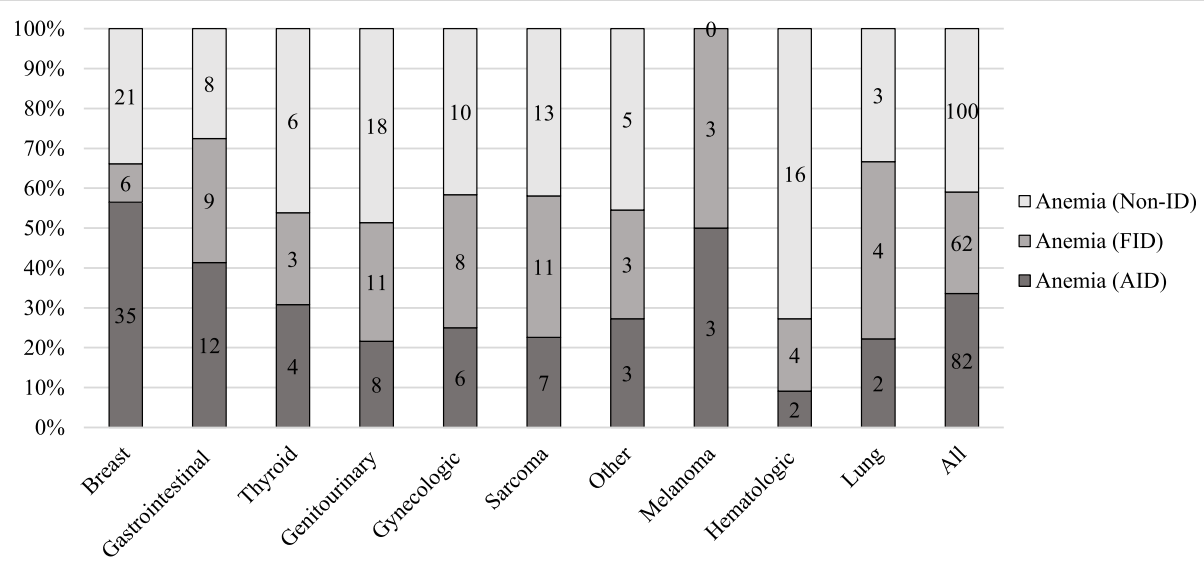

AID - absolute iron deficiency; FID - functional iron deficiency; Non-ID - no iron deficiency.

Fig. 3 Anemia in different iron status groups of patients by cancer location. AID - absolute iron deficiency; FID - functional iron deficiency; NonID - no iron deficiency 


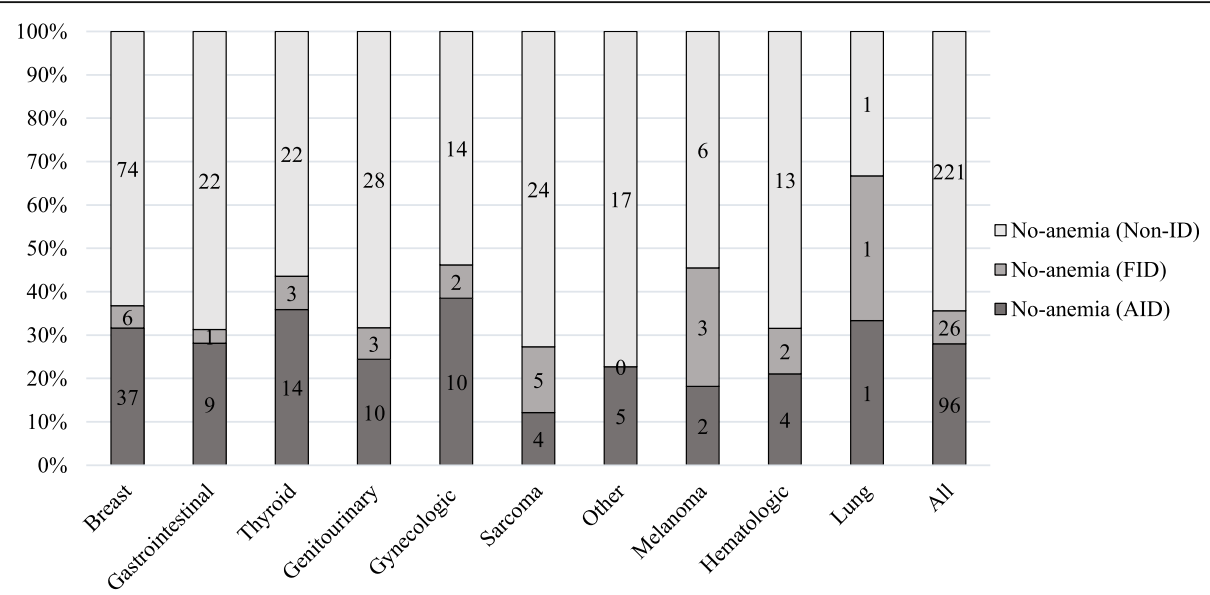

AID - absolute iron deficiency; FID - functional iron deficiency; Non-ID - no iron deficiency.

Fig. 4 Iron status in non-anemic cancer patients. AID - absolute iron deficiency; FID - functional iron deficiency; Non-ID - no iron deficiency

Table 3 Deceased patients' characteristics

\begin{tabular}{|c|c|c|c|}
\hline & $\begin{array}{l}\text { Deceased } \\
n=159(26.5 \%)\end{array}$ & $\begin{array}{l}\text { Alive } \\
n=440(73.5 \%)\end{array}$ & P-value \\
\hline Age (mean $\pm S D$, range) & $63.9 \pm 14.2(21-93)$ & $59.1 \pm 15.3(16.5-90)$ & $p<0.001$ \\
\hline \multicolumn{4}{|l|}{ Gender } \\
\hline Female & $75(47.2 \%)$ & $288(65.5 \%)$ & $p<0.001$ \\
\hline Cancer location & & & $p<0.001$ \\
\hline Genitourinary (GU) & $27(17.0 \%)$ & $53(12 \%)$ & \\
\hline Sarcoma & $27(17.0 \%)$ & $40(9 \%)$ & \\
\hline Gastrointestinal (Gl) & $21(13.2 \%)$ & $42(9.5 \%)$ & \\
\hline Gynecologic (Gyn) & $21(13.2 \%)$ & $29(6.6 \%)$ & \\
\hline Breast & $20(12.6 \%)$ & $161(36.6 \%)$ & \\
\hline Thyroid & $11(6.9 \%)$ & $42(9.5 \%)$ & \\
\hline Lung & $8(5.0 \%)$ & $4(0.9 \%)$ & \\
\hline Hematologic (Hem) & $8(5.0 \%)$ & $33(7.5 \%)$ & \\
\hline Melanoma & $6(3.8 \%)$ & $12(2.7 \%)$ & \\
\hline Other & $10(6.3 \%)$ & $24(5.5 \%)$ & \\
\hline BNP elevation & $139(89.1 \%)$ & $324(74.1 \%)$ & $p<0.001$ \\
\hline \multicolumn{4}{|l|}{ LV dysfunction } \\
\hline LVEF $<50 \%$ & $33(20.8 \%)$ & $74(16.8 \%)$ & $p=0.267$ \\
\hline $\mathrm{GFR}<60 \mathrm{ml} / \mathrm{min} / 1.73 \mathrm{~m}^{2}$ & 39 (24.5\%) & $80(18.2 \%)$ & $p=0.086$ \\
\hline TSAT (mean \pm SD, range, \%), & $21.9 \pm 16.3(3.0-99.0)$ & $23.3 \pm 13.2(4.0-94.0)$ & $p=0.313$ \\
\hline Median & 20 & 20 & \\
\hline Ferritin $(\mu \mathrm{g} / \mathrm{L})$ (mean $\pm \mathrm{SD}$, range) & $245 \pm 319.4(11.0-1500)$ & $167.4 \pm 287.3(6-1500)$ & $p=0.005$ \\
\hline Ferritin $<100 \mu \mathrm{g} / \mathrm{L}$ & $71(44.6 \%)$ & $272(61.8 \%)$ & \\
\hline Ferritin $\geq 100 \mu \mathrm{g} / \mathrm{L}$ & $87(54.7 \%)$ & $165(37.5 \%)$ & \\
\hline Serum iron $(u m o l / L)($ mean \pm SD.range $)$ & $12.6 \pm 8.2(1.6-54.2)$ & $14.9 \pm 7.7(1.7-76)$ & $p=0.002$ \\
\hline Iron $<12 \mathrm{umol} / \mathrm{L}$ & $93(58.5 \%)$ & $159(36.1 \%)$ & \\
\hline Anemia & 94 (59.1\%) & 150 (34.1\%) & $p=0.740$ \\
\hline
\end{tabular}

Some data was missing: there was no data about ferritin concentration of 1 and BNP of 3 deceased patients 


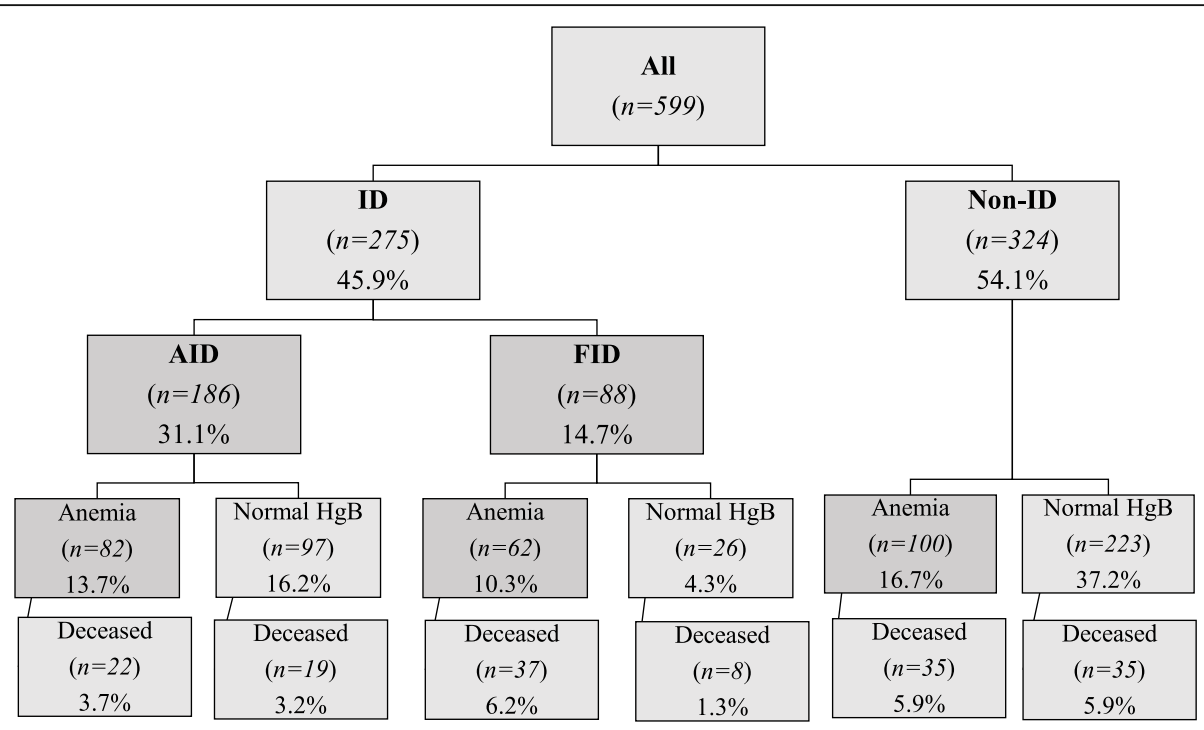

ID - iron deficiency; AID - absolute iron deficiency; FID - functional iron deficiency; Hgb - hemoglobin concentration.

Fig. 5 Iron metabolism parameters and their relation to survival. ID - iron deficiency; AID - absolute iron deficiency; FID - functional iron deficiency; Hgb - hemoglobin concentration

For a more accurate evaluation of ID subgroups, Creactive protein, hepcidin, and soluble transferrin receptors concentration would be helpful, but these analyses were unavailable $[24,25]$.

Unfortunately, there is no data about iron therapy in these patients, which may have had a prognostic impact.

\section{Conclusion}

Iron deficiency and anemia are common in cancer patients referred to a cardio-oncology service. The highest ID rates were in patients with breast, gastrointestinal, genitourinary cancer, and sarcoma. AID was detected more often than FID. FID more frequently was associated with breast cancer, anemia, and worse survival prognosis, whereas AID - with female gender, anemia, and diabetes. Low transferrin saturation, ferritin $\geq 100 \mu \mathrm{g} / \mathrm{L}$, iron level $<12 \mu \mathrm{mol} / \mathrm{L}$, functional iron deficiency, and anemia independently predicted all-cause death.

Future studies are required to confirm ID as a risk factor and evaluate iron replacement therapy's clinical benefits.

Table 4 Factors affecting survival

\begin{tabular}{llll}
\hline Factor & Category & HR (95\% Cl) & P-value \\
\hline Gender & Male & $1.704(1.207-2.404)$ & $\boldsymbol{p}=\mathbf{0 . 0 0 2}$ \\
Age & & $1.016(1.004-1.028)$ & $\boldsymbol{p}=\mathbf{0 . 0 1 1}$ \\
Previous cancer history & Yes & $1.879(1.079-3.272)$ & $\boldsymbol{p}=\mathbf{0 . 0 2 6}$ \\
BNP & Elevated & $2.126(1.258-3.590)$ & $\boldsymbol{p}=\mathbf{0 . 0 0 5}$ \\
LVEF & $<50 \%$ & $1.101(0.721-1.683)$ & $p=0.655$ \\
GFR & $<60 \mathrm{ml} / \mathrm{min} / 1.73 \mathrm{~m}^{2}$ & $1.255(0.838-1.879)$ & $p=0.270$ \\
TSAT & $<20 \%$ & $1.721(1.214-2.439)$ & $\boldsymbol{p}=\mathbf{0 . 0 0 2}$ \\
Ferritin & $20-100 \mu \mathrm{g} / \mathrm{L}$ & $1.004(0.532-1.892)$ & $p=0.991$ \\
& $\geq 100 \mu \mathrm{gg} / \mathrm{L}$ & $2.008(1.088-3.706)$ & $\boldsymbol{p}=\mathbf{0 . 0 2 6}$ \\
ID & FID & $2.538(1.162-3.981)$ & $\boldsymbol{p}<\mathbf{0 . 0 0 1}$ \\
Serum iron & $<12 \mathrm{umol} / \mathrm{L}$ & $2.292(1.614-3.255)$ & $\boldsymbol{p}<\mathbf{0 . 0 0 1}$ \\
Anemia & Yes & $2.462(1.734-3.495)$ & $\boldsymbol{p}<\mathbf{0 . 0 0 1}$ \\
\hline
\end{tabular}

HR Hazard ratio, BNP Brain natriuretic peptide, LVEF Left ventricular ejection fraction, GFR Glomerular filtration rate, TSAT Transferrin saturation, ID Iron deficiency, FID Functional iron deficiency 


\section{Abbreviations}

AH: Arterial hypertension; AID: Absolute iron deficiency; BNP: Brain natriuretic peptide; CAD: Coronary artery disease; CV: Cardiovascular; DM: Diabetes mellitus; DNA: Deoxyribonucleic acid; FID: Functional iron deficiency; Gl: Gastrointestinal cancer; GFR: Glomerular filtration rate; Gyn: Gynecological cancer; GU: Genitourinary cancer; Hem: Hematological cancer; HF: Heart failure; Hgb: Hemoglobin; HR: Hazard ratio; ID: Iron deficiency; LVEF: Left ventricular ejection fraction; $\mathrm{MCH}$ : Mean corpuscular hemoglobin; MCV: Mean corpuscular volume; Non-ID: No iron deficiency; OR: Odds ratio; RES: Reticuloendothelial system; SAS: Statistical Analysis System; SD: Standard deviation; TSAT: Transferrin saturation; VEGF: Vascular endothelial growth factor; Vs.: Versus

\section{Acknowledgments}

Not applicable.

\section{Authors' contributions}

All authors contributed significantly to the manuscript. EC collected and analyzed data. ARL, JC conception, editing. EC, GS analyzed data. EC wrote the manuscript. All authors provided critique and feedback on the manuscript. All authors read and approved the final version of the manuscript.

\section{Funding}

No funding was used in support of this manuscript.

\section{Availability of data and materials}

All data and materials are available upon request.

\section{Ethics approval and consent to participate}

2011 Cardio-Oncology service in Royal Brompton hospital got local Health Research Authority ethical approval for database collection. All data for this research was collected from a depersonalized database.

\section{Consent for publication}

The manuscript does not contain any individual person's data in any form. All authors consent for publication.

\section{Competing interests}

The authors have no competing interests to declare.

\section{Author details}

${ }^{1}$ Clinic of Cardiac and Vascular Diseases, Institute of Clinical Medicine, Faculty of Medicine, Vilnius University, M.K.Čiurlionis str. 21, 03101 Vilnius, Lithuania. ${ }^{2}$ Cardio-Oncology Clinic at Royal Brompton Hospital, London, UK. ${ }^{3}$ Imperial College London, London, UK.

Received: 15 September 2020 Accepted: 19 November 2020

Published online: 02 December 2020

\section{References}

1. Ponka P. Cellular iron metabolism. Kidney Int. 1999;55:S2-11 [cited 2019 11th May] Available from: https://www.sciencedirect.com/science/article/pii/ S0085253815462301.

2. Hentze MW, Muckenthaler MU, Galy B, Camaschella C. Two to tango: regulation of Mammalian iron metabolism. Cell. 2010;142(1):24-38 [cited 2019 11th May] Available from: http://www.ncbi.nlm.nih.gov/pubmed/20603012

3. Dignass A, Farrag K, Stein J. Limitations of Serum Ferritin in Diagnosing Iron Deficiency in Inflammatory Conditions. Int J Chronic Dis. 2018;2018:1-11 [cited 2019 May 11]. Available from: https://www.hindawi.com/journals/ ijcd/2018/9394060/.

4. Naoum FA. Iron deficiency in cancer patients. Rev Bras Hematol Hemoter. 2016;38(4):325-30 [cited 2019 May 11] Available from: http://www.ncbi.nlm. nih.gov/pubmed/27863761.

5. Torti SV, Torti FM. Iron and cancer: more ore to be mined. Nat Rev Cancer. 2013;13(5):342-55 [cited 2019 May 11] Available from: http://www.ncbi.nlm. nih.gov/pubmed/23594855.

6. Aapro M, Österborg A, Gascón P, Ludwig H, Beguin Y. Prevalence and management of cancer-related anemia, iron deficiency and the specific role of i.v. iron. Ann Oncol. 2012;23(8):1954-62 [cited 2019 11th May] Available from: https://academic.oup.com/annonc/article-lookup/doi/10.1093/annonc/ mds112.
7. Fillet G, Beguin Y, Baldelli L. Model of reticuloendothelial iron metabolism in humans: abnormal behavior in idiopathic hemochromatosis and in inflammation. Blood. 1989;74(2):844-51.

8. Alkhateeb AA, Connor JR. The significance of ferritin in cancer: Anti-oxidation, inflammation and tumorigenesis. Biochim Biophys Acta - Rev Cancer. 2013; 1836(2):245-54 [cited 2019 May 11] Available from: https:/www.sciencedirect. com/science/article/abs/pii/S0304419X13000395?via\%3Dihub.

9. Klip IT, Comin-Colet J, Voors AA, Ponikowski P, Enjuanes C, Banasiak W, et al. Iron deficiency in chronic heart failure: An international pooled analysis. Am Heart J. 2013;165(4):575-582.e3 [cited 2019 May 11] Available from: https:// www.sciencedirect.com/science/article/pii/S0002870313000744.

10. Zhang C, Zhang F. Iron homeostasis and tumorigenesis: molecular mechanisms and therapeutic opportunities. Protein Cell. 2015;6(2):88-100 [cited 2019 May 11] Available from: http://www.ncbi.nlm.nih.gov/ pubmed/25476483.

11. Wish JB. Assessing iron status: beyond serum ferritin and transferrin saturation. Clin J Am Soc Nephrol. 2006;1 Suppl 1(Supplement 1):S4-8 [cited 2019 11th May] Available from: http://www.ncbi.nlm.nih.gov/pubmed/17699374.

12. Ludwig H, Müldür $E$, Endler $G$, Hübl W. Prevalence of iron deficiency across different tumors and its association with poor performance status, disease status and anemia. Ann Oncol Off J Eur Soc Med Oncol. 2013;24(7):1886-92 [cited 2019 11th May] Available from: http://www.ncbi.n/m.nih.gov/ pubmed/23567147.

13. Stein J, Hartmann F, Dignass AU. Diagnosis and management of iron deficiency anemia in patients with IBD. Nat Rev Gastroenterol Hepatol. 2010; 7(11):599-610 [cited 2019 May 11] Available from: http://www.nature.com/ articles/nrgastro.2010.151.

14. Grotto HZW. Anaemia of cancer: an overview of mechanisms involved in its pathogenesis. Med Oncol. 2008;25(1):12-21 [cited 2019 May 11] Available from: http://link.springer.com/10.1007/s12032-007-9000-8.

15. Brownlie T, Utermohlen $V$, Hinton PS, Haas JD. Tissue iron deficiency without anemia impairs adaptation in endurance capacity after aerobic training in previously untrained women. Am J Clin Nutr. 2004;79(3):437-43 [cited 2019 May 11] Available from: https://academic.oup.com/ajcn/article/ 79/3/437/4690138

16. Moliner $P$, Jankowska EA, van Veldhuisen DJ, Farre $N$, Rozentryt $P$, Enjuanes $C$, et al. Clinical correlates and prognostic impact of impaired iron storage versus impaired iron transport in an international cohort of 1821 patients with chronic heart failure. Int J Cardiol. 2017;243:360-6 [cited 2019 May 11] Available from: http://www.ncbi.nlm.nih.gov/pubmed/28511855.

17. Abiri B, Vafa M. Iron deficiency and Anemia in Cancer patients: the role of Iron treatment in anemic Cancer patients. Nutr Cancer. 2020;72(5):864-72. https://doi.org/10.1080/01635581.2019.1658794.

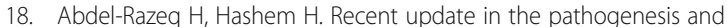
treatment of chemotherapy and cancer induced anemia. Crit Rev Oncol Hematol. 2020;145:102837, ISSN 1040-8428. https://doi.org/10.1016/j. critrevonc.2019.102837.

19. Shpyleva SI, Tryndyak VP, Kovalchuk O, et al. Role of ferritin alterations in human breast cancer cells. Breast Cancer Res Treat. 2011;126:63-71.

20. Mordi IR, Tee A, Lang CC. Iron Therapy in Heart Failure: Ready for Primetime? Card Fail Rev. 2018;4(1):1 [cited 2019 Feb 12] Available from: https://www. cfrjournal.com/articles/iron-therapy-heart-failure-ready-primetime.

21. Ludwig H, Evstatiev R, Kornek G, Aapro M, Bauernhofer T, Buxhofer-Ausch V, et al. Iron metabolism and iron supplementation in cancer patients. Wien Klin Wochenschr. 2015;127(23-24):907-19 [cited 2019 11th May] Available from: http://www.ncbi.nlm.nih.gov/pubmed/26373748.

22. Caro JJ, Salas M, Ward A, Goss G. Anemia as an independent prognostic factor for survival in patients with cancer: a systemic, quantitative review. Cancer. 2001;91(12):2214-21 [cited 2019 May 11] Available from: http:// www.ncbi.nlm.nih.gov/pubmed/11413508.

23. Soliman AT, De Sanctis $V$, Yassin $M$, et al. Iron deficiency anemia and glucose metabolism. Acta Biomed. 2017:88(1):112-8.

24. Wang J, Pantopoulos K. Regulation of cellular iron metabolism. Biochem J. 2011:434(3):365-81.

25. Goodnough LT, Nemeth E, Ganz T. Detection, evaluation, and management of iron-restricted erythropoiesis. Blood. 2010;116:4754-61.

\section{Publisher's Note}

Springer Nature remains neutral with regard to jurisdictional claims in published maps and institutional affiliations. 